\title{
ADVANCES IN APPLIED PROBABILITY VOLUME 40 (2008): INDEX General Applied Probability
}

Adell, J. A., Anoz, J. M. And Lekuona, A. Exact values and sharp estimates for the total variation distance between binomial and Poisson distributions

Allman, E. S., Ané, C. AND Rhodes, J. A. Identifiability of a Markovian model of molecular

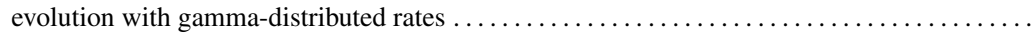

$1032-1046$

$229-249$

Alòs, E. AND EwALD, C. -O. Malliavin differentiability of the Heston volatility and applications to

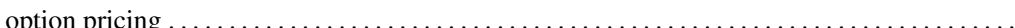

Ané, C. see Allman, E. S.

ANH, V. V., LEONENKo, N. N. AND SHIEH, N. -R. Multifractality of products of geometric Ornstein-

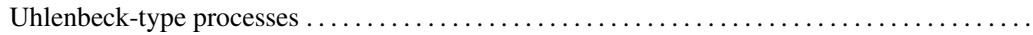

Anoz, J. M. see Adell, J. A.

BÄUERLE, N. AND GRÜBEL, R. Multivariate risk processes with interacting intensities ..........

BLANCHET, J. AND LiU, J. C. State-dependent importance sampling for regularly varying random walks.

Bobrowski, A. Asymptotic behavior of a Feller evolution family involved in the Fisher-Wright

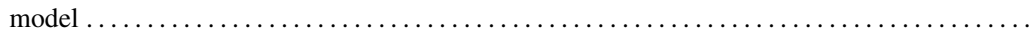

BorovKov, K. AND LAST, G. On level crossings for a general class of piecewise-deterministic Markov

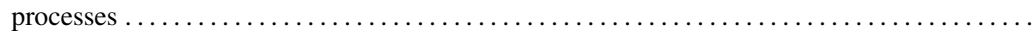

Broman, E. AND MeEster, R. Survival of inhomogeneous Galton-Watson processes ...........

Caramellino, L. and Pacchiarotti, B. Large deviation estimates of the crossing probability for

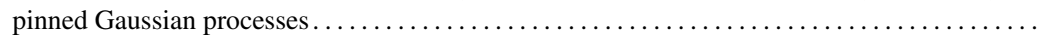

Casella, B. and Roberts, G. O. Exact Monte Carlo simulation of killed diffusions .............

Chakraborty, S. and López-Mimbela, J. A. Nonexplosion of a class of semilinear equations via

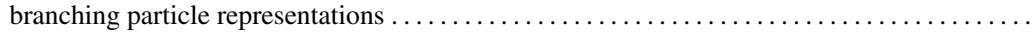

Charalambous, C. and Gittins, J. C. Optimal selection policies for a sequence of candidate drugs

Chen, A. see LI, J.

CrisAn, D. see HeINE, K.

DAI, H. Perfect sampling methods for random forests $\ldots \ldots \ldots \ldots \ldots \ldots \ldots \ldots \ldots \ldots \ldots \ldots$

D'Auria, B. AND Resnick, S. I. The influence of dependence on data network models ..........

Dayanik, S., Powell, W. And Yamazaki, K. Index policies for discounted bandit problems with

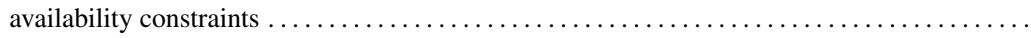

Degen, M. And Embrechts, P. EVT-based estimation of risk capital and convergence of high quantiles

144-162

$1127-1154$

578-601

1102-1126

$734-758$

815-834

798-814

424-453

273-291

250-272

359-376

897-917

60-94

$377-400$

696-715

Dominici, D. E. see KnessL, C.

Embrechts, P. see Degen, M.

Ewald, C. -O. see Alos, E.

Faugeras, O. see Touboul, J.

Fey, A., Van Der Hofstad, R. And Klok, M. J. Large deviations for eigenvalues of sample covariance matrices, with applications to mobile communication systems . . . . . . . . . . .

Frei, C. ANd SchweIzer, M. Exponential utility indifference valuation in two Brownian settings

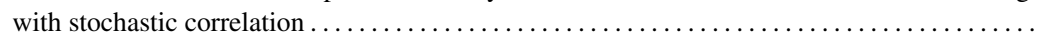

GAMARniK, D. AND MomčIlović, P. Steady-state analysis of a multiserver queue in the Halfin-Whitt

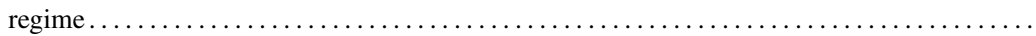

Gentil, I. AND RÉMiLlard, B. Using systematic sampling selection for Monte Carlo solutions of Feynman-Kac equations

1047-1069

$401-423$

548-577

$454-472$ 
Gittins, J. C. see Charalambous, C.

Grassmann, W. K. and Tavakoli, J. Stochastic and substochastic solutions for infinite-state Markov chains with applications to matrix-analytic methods .

$1155-1171$

Griffiths, R. C., Jenkins, P. A. AND Song, Y. S. Importance sampling and the two-locus model

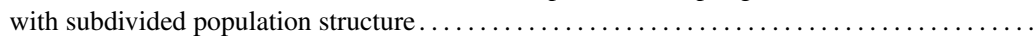

GrüBEL, R. see BÄUERLE, N.

Guillemin, F. M. see Piera, F. J.

HANSEN, J. C. AND JAWORSKI, J. Local properties of random mappings with exchangeable in-degrees

HeINE, K. AND CRISAN, D. Uniform approximations of discrete-time filters . . . . . . . . . . .

IKsanov, A. M. ANd MöHle, M. On the number of jumps of random walks with a barrier.......

IмноF, L. A. Multiple-trial conflicts and stochastic evolutionary game dynamics ............

Janssen, A. J. E. M., Van LeeuwaArden, J. S. H. and Zwart, B. Gaussian expansions and bounds for the Poisson distribution applied to the Erlang B formula $\ldots \ldots \ldots \ldots \ldots \ldots \ldots \ldots \ldots$

JAWORSKI, J. see HANSEN, J. C.

Jenkins, P. A. see Griffiths, R. C.

KLOK, M. J. see FeY, A.

Knessl, C. And Dominici, D. E. Asymptotic analysis of a fluid model modulated by an M/M/1

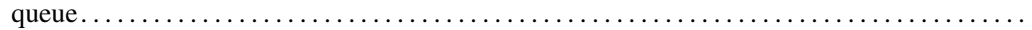

\section{- see SOHN, E.}

Konstantopoulos, T., Kyprianou, A. E., Salminen, P. and Sirviö, M. Analysis of stochastic

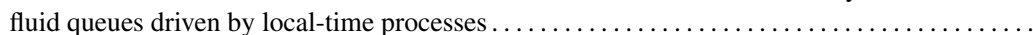

Kyprianou, A. E. see Konstantopoulos, T.

LAST, G. see Borovkov, K.

LeKuONA, A. see Adell, J. A.

LEONEnKo, N. N. see ANH, V. V.

LI, J. AND Chen, A. Decay property of stopped Markovian bulk-arriving queues .............

LiU, J. C. see Blanchet, J.

López-Mimbela, J. A. see Chakraborty, S.

Maller, R. see PARK, H. S.

Mazumdar, R. R. see Piera, F. J.

Mcsweeney, J. K. And Pittel, B. G. Expected coalescence time for a nonuniform allocation process

Meester, R. see Broman, E.

Möhle, M. see Iksanov, A. M.

MomčIlović, P. see GAMARNIK, D.

Pacchiarotti, B. see Caramellino, L.

PARK, H. S. AND Maller, R. Moment and MGF convergence of overshoots and undershoots for

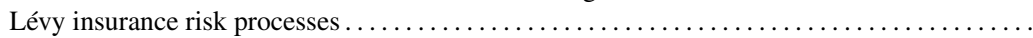

Piera, F. J., Mazumdar, R. R. and Guillemin, F. M. Boundary behavior and product-form stationary distributions of jump diffusions in the orthant with state-dependent reflections....

Pittel, B. G. see Mcsweeney, J. K.

Powell, W. see DAYANIK, S.

QI, X. A functional central limit theorem for spatial birth and death processes $\ldots \ldots \ldots \ldots \ldots \ldots$

RÉmillard, B. see Gentil, I.

RESNICK, S. I. see D'Auria, B.

Rhodes, J. A. see Allman, E. S.

Roberts, G. O. see Casella, B.

Salminen, P. see Konstantopoulos, T.

SchweIzer, M. see Frei, C.

SHIEH, N. -R. see ANH, V. V.

Sirviö, M. see Konstantopoulos, T.

SoHn, E. AND KNESSL, C. The distribution of wasted spaces in the $M / M / \infty$ queue with ranked

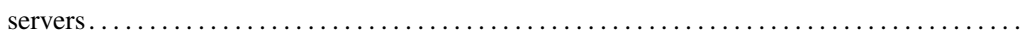

SONG, Y. S. see GRIFFITHS, R. C.

SurgaIlis, D. A quadratic ARCH $(\infty)$ model with long memory and Lévy stable behavior of squares

TAMURA, T. Maximization of the long-term growth rate for a portfolio with fixed and proportional

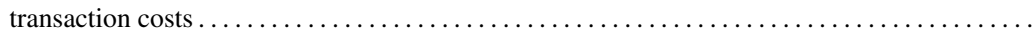


Tavakoli, J. see Grassmann, W. K.

Touboul, J. and Faugeras, O. A characterization of the first hitting time of double integral processes

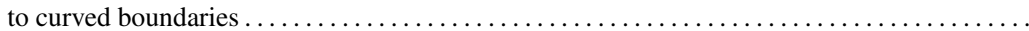

VAN Der Hofstad, R. see Fey, A.

Van LeeuwaArden, J. S. H. see Janssen, A. J. E. M.

VERE-Jones, D. A limit theorem with applications to Båth's law in seismology . .

Wong, S. -K. T. The generalized perpetual American exchange-option problem

YAMAZAKI, K. see DAYANIK, S.

Yu, Y. On an inequality of Karlin and Rinott concerning weighted sums of i.i.d. random variables ZwART, B. see JANSSEN, A. J. E. M. 